\title{
Isolation and Morphological Identification of Apple Anthracnose Fungus of Colletotrichum sp. KV-21
}

\author{
Vivek K. Bajpai ${ }^{1)}$, Seak Won $\mathrm{Choi}^{2)}$, Moon Soo $\mathrm{Cho}^{3)}$, and Sun Chul Kang ${ }^{1)^{*}}$ \\ ${ }^{1)}$ Department of Biotechnology, Daegu University, Kyoungsan, Kyoungbook 712-714, Republic of Korea \\ ${ }^{2)}$ B \& L Agro Co. Ltd., Andong, Kyoungbook 760-300, Republic of Korea \\ ${ }^{3)}$ Department of Horticulture, Daegu University, Kyoungsan, Kyoungbook 712-714, Republic of Korea \\ (Received October 19, 2009, Accepted December 25, 2009)
}

\begin{abstract}
This study was undertaken to isolate and to identify a fungal pathogen Colletotrichum sp. KV-21 associated with apple anthracnose. Rotted Gala apples were used for the isolation of the fungus. The infected tissues were sterilized with $70 \%$ ethanol, washed with sterilized distilled water and were transfemed to $50 \mathrm{ml}$ containing potato broth (PDB) flasks. The peripheral hyphae of the fungal colony which developed from the infected tissues were isolated on to potato dextrose agar (PDA). On PDA plates the fungus grew well at $25^{\circ} \mathrm{C}$ and occupied more than half of a $9 \mathrm{~cm}$ petri dish within 5 days. The fungal cultures on PDA were used for morphological observation and identification of the fungus. Conidiophores were produced on the gray to whitish sporodochial structures scattered on PDA plates which gave rise to conidiogenous cells. The structures of the conidia produced on PDA plates were subcylindrical to obovoid, fusoid, tapered and 4 to $6 \mu \mathrm{m}$ in size.
\end{abstract}

Key Words: Colletotrichum sp. KV-21, anthrocnose, Gala apple, morphological identification

\section{INTRODUCTION}

The genus Colletotrichum comprises some of the most economically important fungi and destructive plantpathogens, such as Colletotrichum acutatum (Simmonds), Colletotrichum fragariae (Brooks), Colletotrichum gloeosporoides (Penz) and Glomerella cingulata (Stoneman), responsible of anthracnose on apple fruits and plants. Apple anthracnose is an important disease hampering the quality and texture of apple fruits worldwide. Colletotrichum spp. can not be distinguished solely by symptoms and signs on infected tissues. Their identification is based on morphological characters. They are comprised of living filaments known as hyphae, or collectively as mycelium. They reproduce by spores which may be sexual or asexual. Colletotrichum spp.

*연락저자:

Tel: +82-53-850-6553 Fax: +82-53-850-6559

E-mail: sckang@daegu.ac.kr are major causes of plant disease, accounting for perhaps $70 \%$ of all the major crop diseases and also known as post-harvest pathogens ${ }^{1}$. Some of these fungal plant pathogens are termed biotrophic because they establish an intricate feeding relationship with living host cells. Others are termed necrotrophic, because they invade the plant tissues aggressively, killing the host cells to obtain nutrients ${ }^{2)}$.

The apple is the pomaceous fruit of the apple tree, species Malus domestica in the rose family Rosaceae which has potential nutritive and therapeutic values. Research suggests that apples may reduce the risk of colon cancer, prostate cancer and lung cancer ${ }^{3)}$. Compared to many other fruits and vegetables, apples contain relatively low amounts of Vitamin $C$ as well as several other antioxidant compounds ${ }^{4}$. The fiber content, while less than in most other fruits, helps regulate bowel movements and may thus reduce the risk of colon cancer. They may also help with heart 
disease, weight loss, and controlling cholesterol, as they do not have any cholesterol, have fiber, which reduces cholesterol by preventing re-absorption, and are bulky for their caloric content like most fruits and vegetables ${ }^{5,6)}$. There is evidence that in vitro apples possess phenolic compounds which may be cancerprotective and demonstrate antioxidant activity ${ }^{7)}$. The predominant phenolic phytochemicals in apples are quercetin, epicatechin, and procyanidin $\mathrm{B}^{8}{ }^{8}$.

Colletotrichum establishes infections in apple orchards, typically through wounds caused by insects or mechanically ${ }^{9)}$. Colletotrichum spp. are distributed and propagated in Asia, Europe, USA, Africa and South America. The most destructive symptom caused is apple anthracnose. Anthracnose first manifests as a small superficial, brown, circular spot on the fruit, which gradually expands. As the lesion expands, conidiophores rupture the fruit epidermis, forming small tufts. Infected transplants are capable of spreading the disease from the nursery to the field, where typical anthracnose symptoms are later manifested $^{10)}$. Considerable yield loss can be inflicted by anthracnose under the appropriate environmental and cultural conditions ${ }^{11)}$. The conidiophores often form concentric rings, which radiate outwards from the initial point of infection. Soft ripe fruit, under moist conditions, with become entirely covered by conidial tufts or vegetative mycelium. Under dryer conditions, or on unripe fruits, mycelium is not present and conidial tufts are rare. Eventually affected fruits become mummified, after the whole fruit has discoloured and dehydrated. The spread of the disease to adjacent fruit occurs often, resulting in adhered clusters of mummified fruit which can persist between seasons ${ }^{12}$.

In this study, we isolated a fungal pathogen, associated with apple anthracnose in Gala apples in Korea and on the basis of its morphological features we identified this fungal pathogen as a Colletotrichum sp. KV-21.

\section{MATERIALS AND METHODS}

\section{Fungal material and isolation of the fungal isolate}

In this study, the rotted Gala apples were collected from the local area of Yeongcheon, Kyoungbook, Republic of Korea. Isolates of anthracnose fungi were originally obtained either by direct transfer of conidia with a sterile needle from infected host tissues onto fresh potato dextrose agar (PDA) plates or by transferring infected host tissue samples into fresh 50 $\mathrm{ml}$ containing potato broth (PDB) flasks after surface sterilization with $70 \%$ ethanol for $1 \mathrm{~min}$ and by washing with sterilized distilled water. The plates with conidia or infected host tissue segments were incubated at $25^{\circ} \mathrm{C}$ in darkness for 7-9 days, and hyphal tips from developing colonies, which were in most cases producing conidia of Colletotrichum type, were transferred to fresh PDA slants fro storage and subsequent study. The culture was deposited with an accession number (DU-KV-21) in the culture collection of the Laboratory of Genetic Engineering, Department of Biotechnology, Daegu University, Republic of Korea. Prior to use, fungus was grown on fresh PDA plates at $25^{\circ} \mathrm{C}$ in the dark, and small agar pieces (1-2 $\mathrm{mm}$ diameter) with mycelia were cut from the edge of the advancing colonies for inocula.

\section{Culture media, myelial growth and colony appearance}

The germination and the growth of fungus was maintained on potato dextrose agar (PDA) medium containing per liter $17 \mathrm{~g}$ enzymatic digest of casein, 3 $\mathrm{g}$ enzymatic digest of soybean meal, $5 \mathrm{~g} \mathrm{NaCl}, 2.5 \mathrm{~g}$ dipotassium phosphate and $2.5 \mathrm{~g}$ dextrose in sterile distilled water.

Colony colors of the fungal isolates were described from isolates incubated at $25^{\circ} \mathrm{C}$ in dark. Three plates were used to determine the radial mycelial growth of fungal isolate.

\section{Morphological observation}

Isolates of the fungus were incubated at $25^{\circ} \mathrm{C}$ in dark. Cultures were transferred to fresh potato dextrose agar (PDA) to stimulate sporulation of conidia and facilitate identification. Morphological observations were made from structures mounted in lacto-phenol. The conidial measurements were derived from observations at 400x magnification (Nikon, Alphaphot-2/YS2, Shanghai, China).

\section{RESULTS AND DISCUSSION}

Abundant anthracnose infestations have been evident in several host plants and many countries during the summer seasons including apple fruits and plants. 
This has resulted in massive collapse of economically important host plants. Colletotrichum spp. are known to have a wide host range and geographic distribution. Exact identification of apple anthracnose pathogens (Colletotrichum spp.) of fruit trees should be based on laboratory studies as well as field observations of disease epidemiology and symptomatology. These studies are necessary because the fungal organs we usually find on diseased plants tissues in the field are almost always the anamorphs or conidia of the Colletotrichum type, which are morphologically simple and similar to each other for different species ${ }^{13-15)}$.

Colletotrichum spp. causing apple anthracnose, are predominantly the pathogens of fruit, stolons and crowns. We made an attempt to morphologically characterize a Colletotrichum sp. The fungus isolated here in this study from the rotted Gala apples of Yeongcheon area, Kyounbook, Republic of Korea, was identified to be Colletotrichum sp. KV-21 (Fig. 1) through com- paring its morphology with the documented description based on its microscopic features ${ }^{16)}$. As shown in Fig. 2, the colony of Colletotrichum sp. KV-21 grew well on fresh PDA medium and maximum mycelial growth was observed at $25^{\circ} \mathrm{C}$ with entire colony margin, filling the whole plate surface in 7 days. The colony was fluffy, grayish white, sporulating well and grayish yellow in reverse. The results of this study strongly support the identity of the fungal isolate as Colletotrichum sp. KV-21 and were identical to the findings of others as evident by mycelial growth and colony appearance ${ }^{16)}$. Lubbe et al. (2004) also characterized the Colletorichum spp., and based on their morphological features these fungi were confirmed to be $C$. acutatum $\mathrm{f}$. sp. hakea, $C$. boninense and these results were also in strong agreement with our findings ${ }^{16)}$.

Aerial mycelium of Colletotrichum spp. at first sparse, later developing concentric zones of dense mycelium
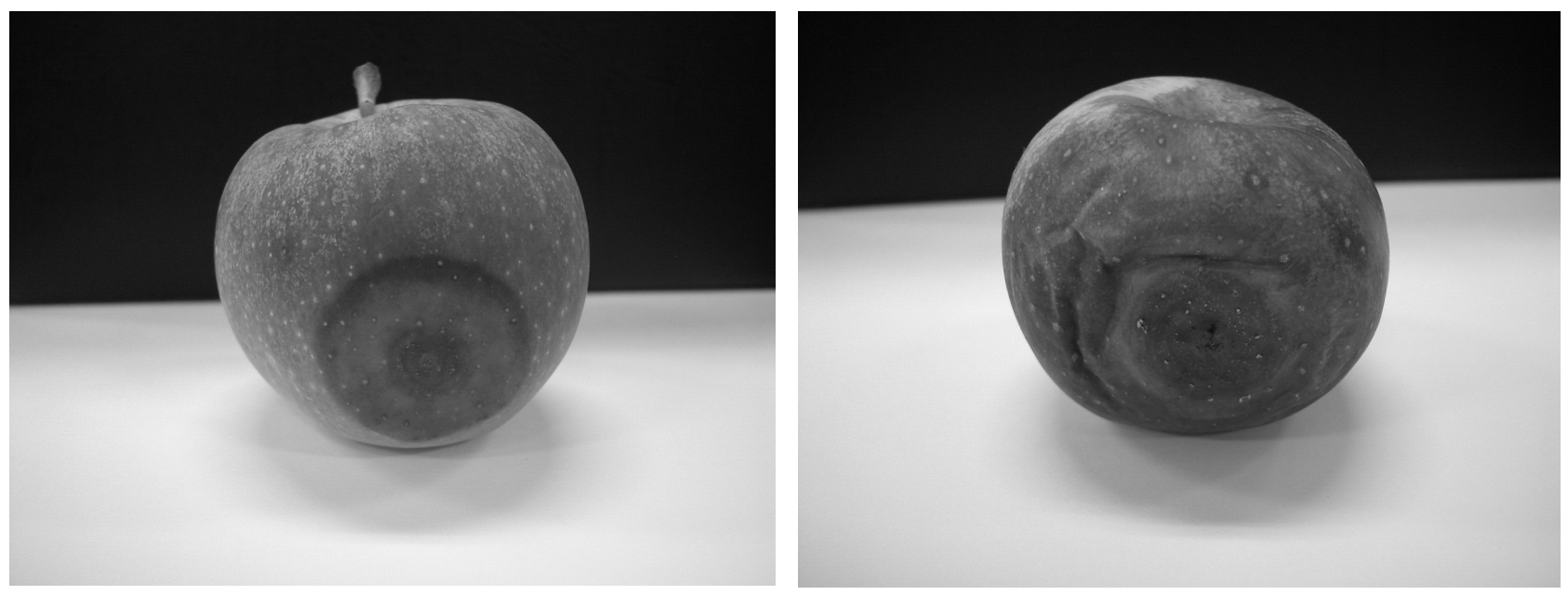

Fig. 1. Apple anthracnose of Gala apples collected from the local area of Yeongcheon City, Kyoungbook, Republic of Korea.

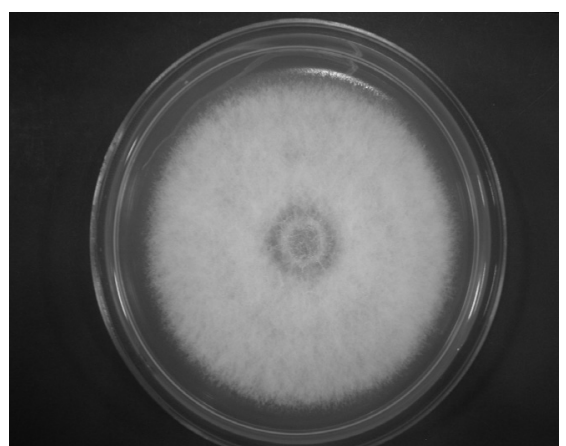

(a) Front: grayish white

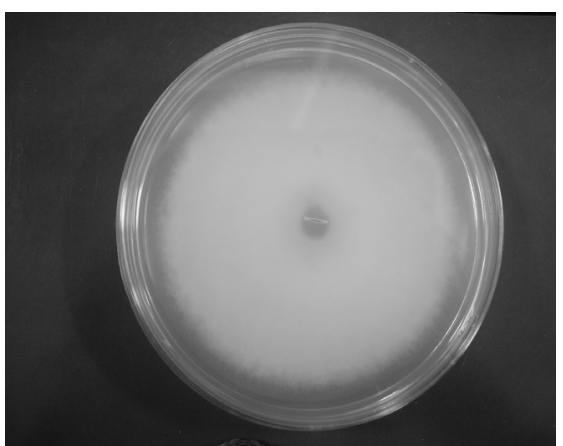

(b) Reverse: grayish yellow

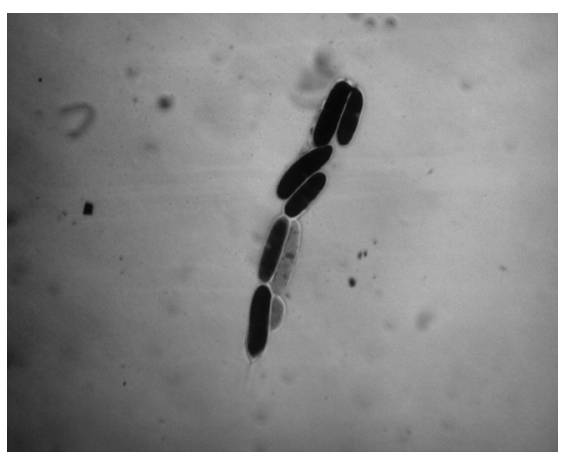

(c) Conidia of Colletotrichum sp. KV-21

Fig. 2. Colonies and morphology of the isolate of Colletotrichum sp. KV-21 isolated from the rotted Gala apples. 
and light buff sporogenous tissue, but in many isolates only darkening of the mycelium with age occurs ${ }^{12,17)}$. Primary hyphae at advancing edge of colony are thin-walled with one or more branches initiated before the first septum with dense and granular contents. Secondary and subsequent branch hyphae are often much narrower than primary hyphae ${ }^{17,18)}$.

As shown in Fig. 2, on fresh PDA, the conidia of Colletotrichum sp. KV-21 were subcylindrical, to abovoid, fusoid, hyaline, smooth with 4 to $6 \mu \mathrm{m}$ in size and generally tapering from the lower part towards a truncate apex, which the unique feature of genus Colletotrichum. Several researchers have been reported these conidial characteristics of Colletotrichum spp. as also evident by the findings of others ${ }^{16)}$. On the host, conidial sporodochia occur on all infected organs; discrete sclerotia are not usually formed, but infected fruits develop dry substratal stromata ('mummies') in which a stromatic layer replaces most of the pericarp ${ }^{19)}$. Although, acervular conidiomata were not present, all strains produced conidiogenous cells directly on the agar surface and/or throughout the aerial mycelium of the colony ${ }^{15)}$.

The presence of pathogen on apple fruits probably occurred when fungus enzymatically penetrates the cuticle and then remains as sub-cuticular hyphae until the post climacteric stage of fruit growth is attained. Grover and Bansal (1970) reported the isolation of $C$. capsici from the rotten stems, leaves and seeds of $C$. frutescens ${ }^{20)}$. Wahid (2001) had also reported that the pathogen apple anthracnose has a wide host range, which includes mango, pear and guava fruits ${ }^{21)}$. The attack of fruits by Colletotrichum spp. inducing anthracnose diseases especially in the rainy season has been reported $^{22)}$. Nevertheless, despite the fact that Colletotrichum affect a wide spread number of cultures, its pathogenic range increases caused by a rising number of species identified under this Genus that were classified as anthracnose's agent ${ }^{23)}$.

Colletotrichum spp. an ubiquitous pathogen infecting several crops causing anthracnose diseases. It is possible that insect vectors are involved in dissemination of the pathogens propergule into the plant during pollination or during feeding on the fruits. Adelaja (1997) reported that fruit fly stings enhance the entry of Colletotrichum spp. into African star apple fruits by their oviposition on the fruits ${ }^{24)}$. The prevalence and the rapid spread of these diseases during the peak of the rainy season could be due to the humid condition prevailing at that time of the year, which supports the rapid production of conidia. Colletotrichum spp. have been reported to cause rapid infection during heavy dew or rain fall ${ }^{25,26)}$. Reasons for the above observation might be related to the fact that rainfall or rain-splash probably played an important role in the dispersal of the pathogen's propagules in the field.

On the other hand, market survey has revealed that the anthracnose infected fruits attracted low prices $^{27)}$. The industrial use of apple fruits in jam, cheese, ice cream, apple chutney, apple crisp and pies will be unattainable if the apple fruits produced are of low quality due to fungal infection. Changes in nutrient composition caused by fungal infection of the apple fruits will also adversely affect their uses for several apple food products. While its commercial or market value as a means of lively hood to peasant farmers the women and the children will equally be affected. Therefore, identification of apple anthracnose fungi which cause severe losses to pome and stone fruits including Gala apple fruits would be an addition to plant pathology to understand the disease range of such pathogens in pre- and post-harvest technology. Thus, based on the aforementioned morphological as well as phytopathological characteristics, the isolated fungus was characterized as Colletotrichum sp. KV-21 However, further study is warranted on the identification Colletotrichum sp. KV-21 at molecular levels to further authenticate the outcomes of this study.

\section{ACKNOWLEDGEMENT}

This study was supported by Technology Development Program for Agriculture and Forestry, Ministry for Agriculture, Forestry and Fisheries, Republic of Korea.

\section{REFERENCES}

1. IAPSC, (1985) Colletotrichum fructicola. Distribution maps of major crop pests and diseases in Africa No. 306. IAPSC, Yaounde, Cameroon, South Africa.

2. Deacon, J. W. (1997) Modern Mycology. Blackwell Scientific, Oxford, UK.

3. Nutrition to Reduce Cancer Risk (NRCR), (2008) 
The Stanford Cancer Center (SCC). http:/ /cancer.stanford. edu/information/nutritionAndCancer/reduceRisk/.

4. Boyer, J. and Liu, R. H. (2004) Apple phytochemicals and their health benefits. Nutr. J. (Cornell University, Ithaca, New York 14853-7201), USA.

5. Sharma, R. (2005) Improve your health with Apple, Guava, Mango. Diamond Pocket Books (P) Ltd. pp. 22. ISBN 8128809245.

6. Apples Keep Your Family Healthy (AKYFH), (2008) Washington State Apple Advertising Commission. http://www.bestapples.com/healthy/.

7. Lee, K. W., Lee, S. J., Kang, N. J., Lee, C. Y. and Lee, H. J. (2004) Effects of phenolics in Empire apples on hydrogen peroxide-induced inhibition of gap-junctional intercellular communication, Biofactors 21, 361-365.

8. Lee, K. W., Kim, Y. J., Kim, D. O., Lee, H. J. and Lee, C. Y. (2003) Major phenolics in apple and their contribution to the total antioxidant capacity, J. Agric. Food Chem. 51(22), 6516-6520.

9. Elmer, P. A. G. and Gaunt, R. E. (1986) A survey of fungicide insensitivity in Colletotrichum fructicola. Proceedings of the 39th New Zealand weed and pest control conference, pp. 166-169.

10. Henz, G. P., Boiteux, L. S. and Lopes C. A. (1992) Outbreak of strawberry anthracnose caused by Colletotrichum acutatum in central Brazil. Plant Dis. 76, 212.

11. Howard, C. M., Maas, J. L., Chandler, C. K. and Albregts, E. E. (1992) Anthracnose of strawberry caused by the Colletotrichum complex in Florida. Plant Dis. 76, 976-981.

12. Byrde, R. J. W. and Willetts, H. J. (1977) The brown rot fungi of fruit. Pergamon Press, London, UK.

13. Ogawa, J. M., Zehr, E. I., Bird, G. W., Ritchie, D. F., Uriu, K. and Uyemoto, J. K. (1995) Compendium of stone fruit diseases. APS, St. Paul, MN, USA.

14. Van Leeuwen, G. C. M. and van Kesteren, H. A. (1998) Delineation of the three brown rot fungi of fruit crops (Colletotrichum spp.) on the bases of quantitative characteristics, Can J. Bot. 76, 2042-2050.

15. Wormald, H. (1920) The brown rot diseases of fruit trees, with special reference to two biologic forms of Monilia cinerea, Bon. II, Annu. Bot. 34, 143-171.
16. Lubbe, C. M., Denman, S., Cannon, P. F., Groenewald, J. Z., Lamprecht, S. C. and Crous, P. W. (2004) Characterization of Colletotrichum species associated with diseases of Proteaceae, Mycologia, 96(6), 1268-1279.

17. Hashmi, M. H., Morgan-Jones, G. and Kendrich, B. (1972) Conidium ontogeny in Hyphomycetes: Monilia state of Neurospora sitophila and Sclerotinia laxa, Can. J. Bot. 50, 2419-2421.

18. Penrose, L. J., Tarran, J. and Wong, A. L. (1976) First record of Sclerotinia laxa in New South Wales: differentiation from $S$. fructicola by cultural characteristics and electrophoresis, Aus. J. Agric. Res. 27, 547-556.

19. Mordue, J. E. M. (1979) Sclerotinia fructicola, S. fructigena, S. laxa. CMI Descriptions of pathogenic fungi and bacteria Nos. 616, 617, 619. CAB International, Wallingford, UK.

20. Grover, R. K. and Bansal (1970) Seed borne nature of Colletotrichum capsici in chilli seeds and its control by seed dressing fungicides. Ind. Phytopathol. 23, 664-668.

21. Wahid, O. A. A., (2001) Occurrence of Colletotrichum anthracnose disease of guava fruit in Egypt. Int. J. Pest. Mang. 47, 147-152.

22. Morton, J., (1987) Guava. In: Fruits of warm climates. Julia F. Morton and Miamai, F. L., pp: 356-363.

23. Peres, N. A. R., Kurama, E. E., Dias, M. S. C. and de Souza, H. L. (2002). Identification of Colletotrichum spp. affecting fruit after harvest in Brazil. J. Phytopathol. 150, 128-134.

24. Adelaja, B. A. (1997) Observation on the pests and diseases of Chrysopyllum albidum in Nigeria. In: Proceedings of a national workshop on the potentials of the star apple in Nigeria. Denton, O. A., Ladipo, D. O., Adetoro, M. A. and Sarumi M.B. (Eds.), pp: 117-121.

25. Isaque, M. and Talukder, M. J. (1967). Survey of fungal flora of East Pakistan. Agric. Pakistan 18, 17-26.

26. Talukder, M. J. (1974) Plant disease in Bangladesh. Bang. J. Agric. Res. 32, 61-86.

27. Babalola, S. O., Ashaye, O. A., Babalola, A. O. And Aina, J. O. (2002) Effect of cold temperature storage on the quality of Pawpaw and Guava leathers. Afr. J. Biotechnol. 1, 61-63. 